\title{
Systematic introduction of obstetric ultrasound skills into practice
}

\author{
Tiran Dias ${ }^{1}$, Lahiru Ruwanpura ${ }^{2}$ \\ Sri Lanka Journal of Obstetrics and Gynaecology 2011; 33: 154-157
}

\begin{abstract}
Objective: To identify the present skill level of obstetric ultrasound, to set quality standards and to make recommendations in terms of obstetrics ultrasound service improvement.

Methods: An audit was carried out in five provinces in Sri Lanka. At the beginning of the ultrasound workshops, attendees were requested to participate in this audit. Optimum ultrasound machine settings and biometry standards were defined at the beginning. Measures were taken to recruit a cross section of the obstetric service providers including postgraduate trainees and senior house officers (SHOO). They were asked to perform an ultrasound scan and obtain standard images. These images were assessed onsite and documented in structured data sheet. The level of competency was analyzed according to the pre-defined standards. A structured ultrasound training programs have been carried out to improve the existing knowledge and skills of the participants. In order to simulate their own scan environment and habits, participants were assessed without their knowledge in the second phase of this audit.
\end{abstract}

Results: Overall skills in controlling machine settings were very poor. Almost all the participants did not manage to set the machine competently. Postgraduates were slightly better in obtaining correct landmarks for fetal biometry. It is encouraging to note that most of the postgraduates were able to improve their machine setting skills in subsequent audit. First trimester crown-rump length is the least improved fetal biometry in second phase.

Conclusion: At present background skills of obstetric ultrasound are substandard and it can be improved by dedicated training. Systematic

\footnotetext{
${ }^{1}$ Research Fellow in St George's University of London Fetal Medicine Unit St George's University of London SW17 0QT London.

${ }^{2}$ Research Assistant, Faculty of Medicine, University of Colombo, Sri Lanka.

Correspondence: Tiran Dias

E-mail: thiran_dias@yahoo.com
}

introduction of obstetric ultrasound training in to post graduate training is necessary. This will produce a new generation of obstetricians competent in this field. All the newly appointed $\mathrm{SHOO} / \mathrm{MOO}$ in obstetrics need to undergo mandatory training in obstetric ultrasound.

\section{Introduction}

Obstetric ultrasound has now become routine practice in antenatal care. It covers a spectrum of services ranging from antenatal screening for chromosomal aneployides to prediction of adverse outcomes in later pregnancy. Importance of first trimester ultrasound has been widely recognized and most countries have incorporated this practice to their guidelines and offer routine dating and screening for their antenatal population ${ }^{1-5}$ (Table 1).

Table 1. Use of ultrasound in antenatal care in different countries

\begin{tabular}{|c|c|c|}
\hline Country & $\begin{array}{l}\text { Timing of the } \\
\text { Scan }\end{array}$ & $\begin{array}{c}\text { Purpose of } \\
\text { the Scan }\end{array}$ \\
\hline United Kingdom & $\begin{array}{l}11-14 \\
20-24\end{array}$ & $\begin{array}{l}\text { Dating } \\
\text { Anomaly screen }\end{array}$ \\
\hline Portugal and Italy & $\begin{array}{l}11-14 \\
21-23 \\
32-34\end{array}$ & $\begin{array}{l}\text { Dating } \\
\text { Anomaly Scan } \\
\text { Growth scan }\end{array}$ \\
\hline New Zealand & $\begin{array}{l}11-14 \\
20-22 \\
>41\end{array}$ & $\begin{array}{l}\text { Dating and NT } \\
\text { Anomy scan } \\
\text { Post date } \\
\text { assessment }\end{array}$ \\
\hline India & \multicolumn{2}{|c|}{ No universal policy } \\
\hline
\end{tabular}

In order to introduce routine obstetrics ultrasound scanning into the national antenatal policy, it is mandatory to have competent doctors in this field throughout the country. However, there is no systematic obstetric ultrasound training program in Sri Lanka. The need for such a program has long been awaited. In order to plan and implement a new program it is important to assess the existing ultrasound skills in obstetrics care givers. 


\section{Objective}

The objective of this audit is to identify the present skill level of obstetric ultrasound, to set standards of quality, and give recommendations to Postgraduate Institute of Medicine (PGIM), Sri Lanka College of Obstetricians and Gynaecologists (SLCOG), Sri Lanka Obstetric Ultrasound Group (SLOUG) to work out a plan to improve this service.

\section{Methodology}

\section{Phase 1}

This audit was carried out in five provinces in Sri Lanka with the collaboration of SLCOG and SLOUG. In view of teaching/ assessment and audit of obstetric ultrasound skills, five obstetric ultrasound workshops were organized in Galle, Colombo, Kurunegalla, Jaffna, and Badulla. At the beginning of these workshops attendees were requested to participate in this audit and following standards were defined at the beginning.

Ultrasound machine settings: Optimum use of recognized machine setting tools (probe orientation, presets, depth, frequency, gain, focus, frame rate and zoom) were assessed ${ }^{6}$. The candidates were requested to freeze the ultrasound image when they think image is optimum. The competency was categorized in to three levels in terms of their use (competent use, some use, no use).

Fetal biometry: The candidates were expected to acquire ultrasound images of fetal head, abdomen and mid-sagiital section in order to measure the head circumference (HC), abdominal circumference (AC) and the crown-rump length (CRL) respectively. Standards were set according to the established guidelines and competency was assessed in terms of use of correct landmarks ${ }^{6}$.

Measures were taken to recruit a cross section of participants including postgraduate trainees and senior house officers (SHOO) for this audit. They were asked to perform an ultrasound scan and obtain standard images. These images were assessed onsite and documented in structured data sheet. The level of competency was analyzed according to the predefined standards ${ }^{6}$. In view of upgrading present competency level, series of ultrasound training programs were conducted. In parallel with these workshops hands-on program was conducted by the SLOUG members and comprehensive practical hand book was distributed among participants.
Phase 2

In order to assess the improvement of obstetrics ultrasound skills and the progress of these training programs, re-audit was conducted in Colombo. Postgraduate trainees who attended the earlier workshops were reassessed in this second phase. In order to simulate their own scan environment and habits, participants were assessed without their knowledge. Same standards were used to assess the competency as described above ${ }^{6}$.

\section{Results}

A total of 21 candidates participated in this audit, out of which 10 were SHOO, 6 were postgraduate trainees and the rest were consultants, RHOO and MOO. Overall ultrasound machine settings were poor in both SHOO and postgraduate trainees (Figure 1, 2). Even though the general competency in fetal biometry is poor in all candidates, postgraduates were slightly better in taking fetal biometry than SHOO (Figure 3, 4).

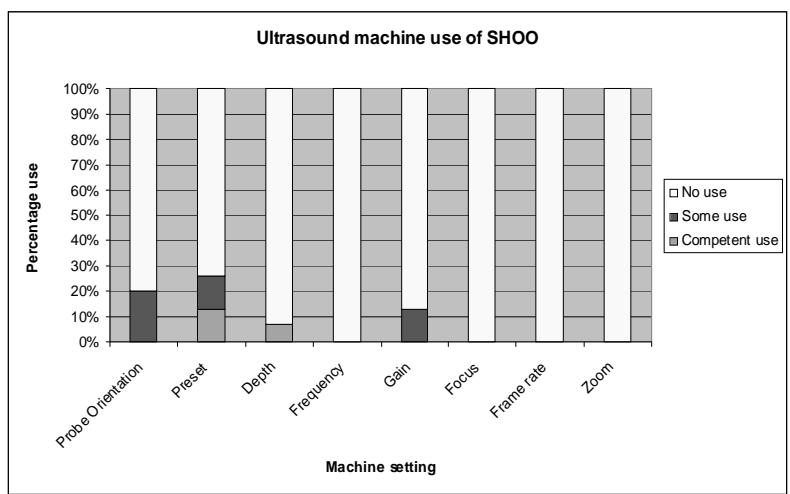

Figure 1. Ultrasound machine setting skills among Senior House Officers (SHOO) in obstetrics before the awareness program (baseline assessment).

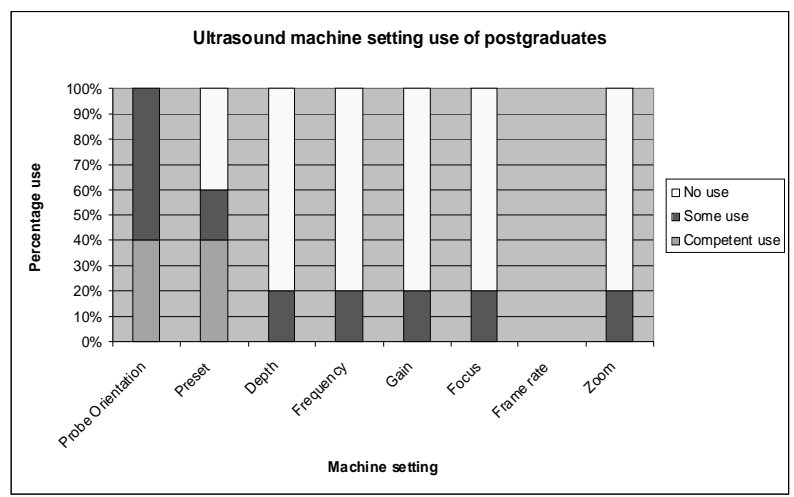

Figure 2. Ultrasound machine setting skills among Postgraduate trainees in obstetrics before the awareness program (baseline assessment). 


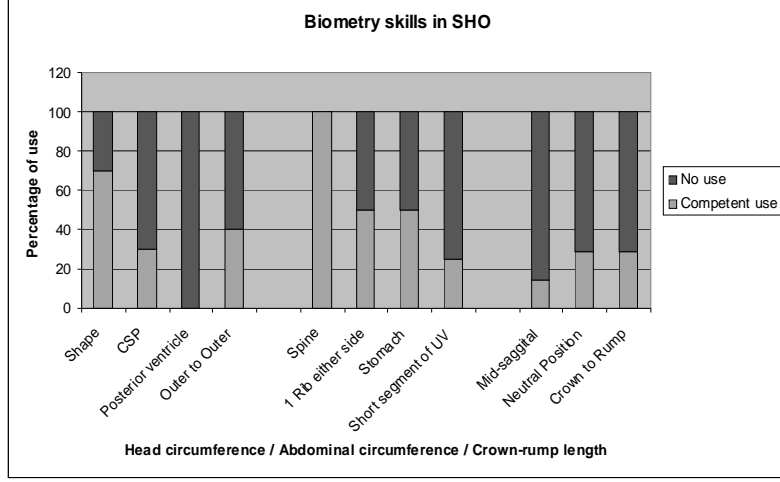

Figure 3. Fetal biometry skills among Senior House Officers in obstetrics before the awareness program (CSP - cavum septum pellucidam) (baseline assessment).

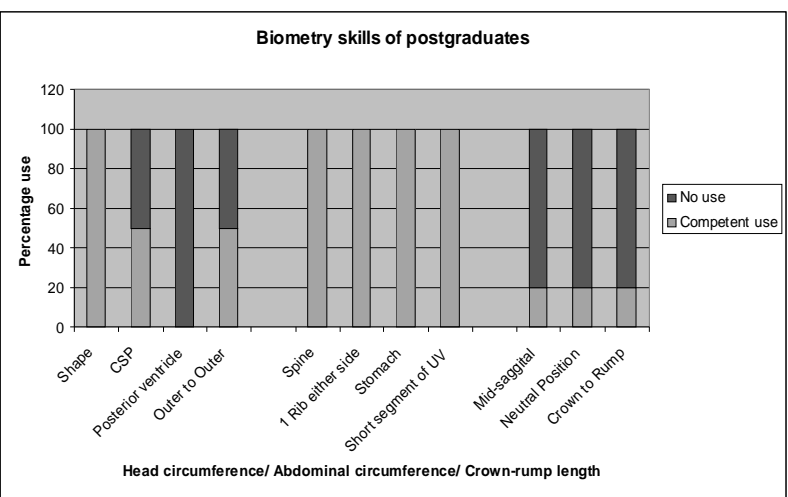

Figure 4. Fetal biometry skills among Postgraduate trainees in obstetrics before the awareness program (CSP - Cavum septum pellucidum) (baseline assessment).

Four out of 6 postgraduate trainees who attended the first audit cycle were reassessed. It is encouraging to observe that most of the postgraduate trainees were able to improve their machine setting skills in subsequent audit (Figure 5). Optimum image for fetal HC measurement has been improved in terms of caliper placement (Figure 6). First trimester crown-rump length is the least improved fetal biometry in second phase.

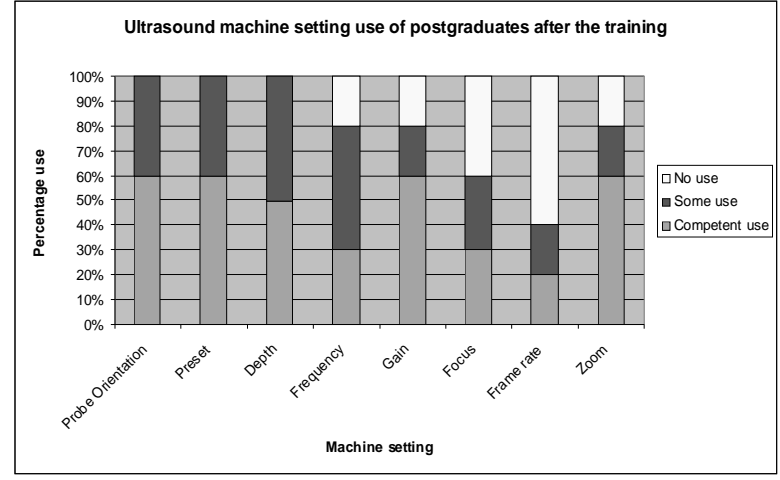

Figure 5. Ultrasound machine setting skills among Postgraduate trainees in obstetrics after the awareness program (completion of the cycle).

\section{Discussion and recommendations}

At present, background skills in obstetric ultrasound are substandard and it can be improved by dedicated training. It is essential to acquire a certain level of skill in obstetrics ultrasound before contemplating obstetrics scans. Substandard scanning would do more harm than any benefit. Systematic introduction of obstetric ultrasound training in to postgraduate training is necessary. This will produce a new generation of obstetricians competent in this field. All the newly appointed SHOO/MOO in

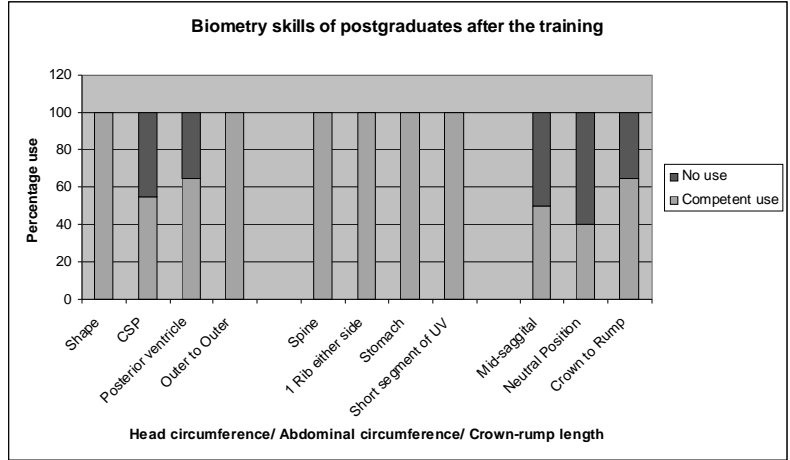

Figure 6. Fetal biometry skills among postgraduate trainees in obstetrics after the awareness program (CSP - cavum septum pellucidam) (completion of the cycle).

obstetrics need to undergo mandatory training in obstetric ultrasound. In order to improve ultrasound skills in obstetricians, we should recognize the reality of poor skill level of obstetric ultrasound. Appropriate systematic approach is needed in terms of training in ultrasound skills. This will require the coordinated efforts of the SLCOG, PGIM, SLOUG and the Ministry of Health. This entire program should be supported and coordinated by a competent authority. Training, assessment and audit of this training program should be designed to cover the following categories. 


\section{For present Consultants/Trainees}

SLCOG/PGIM/SLOUS has to devise a system to conduct more peripheral workshops/hands-on sessions for the consultants/postgraduates/SHOO. These training needs to be audited on a regular basis and any perceived deficiencies need to be addressed in subsequent workshops.

\section{Future Post Graduate Trainees}

PGIM should allocate every new postgraduate trainee to a recognized obstetric ultrasound trainer from the SLOUG. These trainers should be responsible to train these trainees.

\section{Future SHOO/MOO in Obstetrics}

SLCOG should liaise with the Ministry of Health to start training programs to the $\mathrm{SHOO} / \mathrm{MOO}$.

\section{Acknowledgements}

We would like to acknowledge all the members of the Sri Lanka Obstetric Ultrasound Group and to Prof. Hemantha Senanayake, Dr. Ananda Ranathunga,
Dr. Sunil Fernando, Dr. Sanath Lanerolle, Dr. Nishendra Karunarathne, Dr. Rameez Farukan and Raffaele Napolitano for their participation in above workshops.

\section{References}

1. National Collaborating Centre for Women's and Children's Health Clinical Guideline March 2008.

2. http://www.nice.org.uk/nicemedia/pdf/CG62 Full GuidelineCorrectedJune2008.pdf

3. Dias T. Importance of first trimester scan. Pregnancy dating - why, when and how. Sri Lanka Journal of Obstetrics and Gynaecology 2011; 33(1): 33-7.

4. Dias T. Importance of first trimester scan - Twin pregnancy. Sri Lanka Journal of Obstetrics and Gynaecology 2011; 33(2): 72-6.

5. Dias T, Mahsud-Dornan D, Thilaganathan B, Papageorghiou A, Bhide A. First trimester ultrasound dating of twin pregnancy: are singleton charts reliable? BJOG 2010; 117: 979-84.

6. Chudleigh T, Thilaganathan B. Routine second trimester screening - assessing gestational age. In Obstetric Ultrasound: How, Why and When (3rd edn), Elsevier, Churchill Livingston: London, 2004; 98-107. 